\section{Series Discharge Tubes*}

By Dr. H. Greinacher

IF the terminals of a lightning arrester of the horn form are connected with the poles of a step transformer

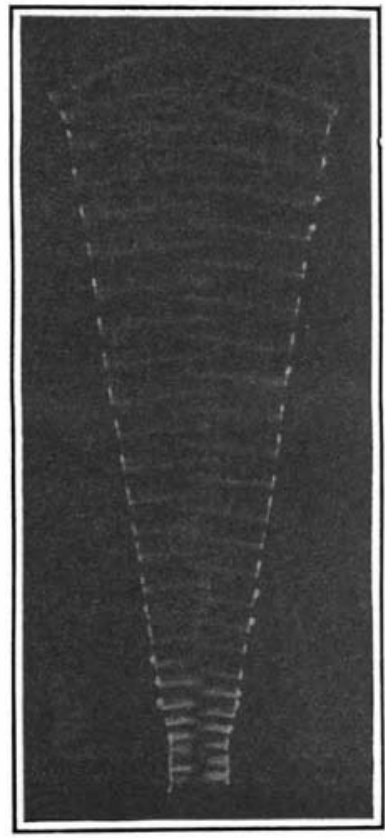

Fig. 1.-Alternating discharge between horn electrodes.

or an induction coil fed with an alternating current, a luminous arc forms between the bases of the horns, travels upward to their summits, breaks, and instantly recommences at the bases. Although the ascent of the are is comparatively slow, occupying about one second with a

* Translated for the Scifntific AMErican Supplement from Elektrotechnische Zeitschrift.

\section{Fraudulent Playing Cards*}

By Friedrich Januschke

IN cheating at cards, as in playing the violin, no amount of practice can supply the place of genius. This fact was forcibly impressed upon me by an examination of some fraudulent cards in the criminal institute of the University of Graz. It appears impossible to acquire, by practice alone, skill in cheating with these cards, so slight and inconspicuous are the differences by which the backs of the cards are distinguished. Some degree of genius, or innate predisposition is requisite for sucoss.

I was confirmed in this opinion by experiments. I showed a pack of false cards to two men, pointing out all of the differentiating marks and explaining what they signified and how they were to be used. Then I asked the men to cheat me with these cards. One man soon succeeded in cheating me quite easily, without showing any evidence of intense thought or effort f memory, while the other experienced great dificulty in remembering the marks, and continually made misin rem

Cards are marked in many different ways. For example, the king of hearts may bear a faint imprint of the finger nail at the middle of one side of the back while the king of clubs is marked similarly at both sides, the king of diamonds at both sides and the top and the king of spades at both sides, top and bottom.

In another fraudulent pack the queens may be marked at the edges and the kings at the center. Markings

\section{* Adapted from Die Umschau.}

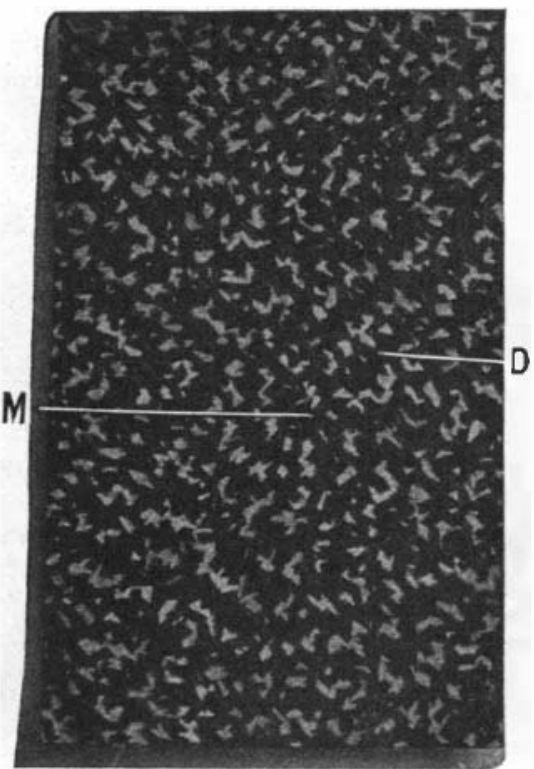

Fig. 1.-Back of card identified by peculiar pattern. current of moderate strength, the separate partial discharges cannot be distinguished by the eye, but a photograph of the phenomenon shows a series of luminous trails starting alternately from each horn.

The partial discharges can be made separately visible by enclosing the horns in a glass vessel filled with rarefied air. In these conditions there is no arc, properly socalled, but each partial discharge produces a pointed bluish glow, and the successive positions of these luminous tongues, springing alternately from the right and left horn, or wire, can be followed directly with the eye. The blue glow always starts from the horn that at the momen is negative, and at the same instant a luminous red spot, called the anode light, appears opposite it on the othe horn. The lively motion and brilliant colors of the dis charge make it a very striking lecture illustration. It can be shown effectively by connecting the secondary wire of a small induction coil capable of giving an 8-inch with an ordinary lighting cimeuit, furnishing an alternating current of 50 cycles per second.

The pressure of the air must be carefully regulated, as the most beautiful effects are obtained with a certain definite pressure. For this reason, it is advisable to use a glass tube of suitable dimensions, evacuated to the proper degree and sealed. The Gundalach firm, of Gehlberg, furnishes such tubes. filled with nitrogen, carbon dioxide, helium and many other gases, and also tube provided with cocks, which may be exhausted by means of a water-jet pump, for the study of the discharge at different pressures.

These tubes not only form very welcome demonstration objects but also are useful for various practical purposes. First. They can be used to determine the character of a current-whether alternating, intermittent direct, or continuous. Every variation in the form of the primary current shows in the succession of partial discharges, so that the series discharge tube constitutes an automatic oscillograph.
Second. The operation of direct current interrupters can be studied and regulated by means of these tubes. Even the extra current on closing the circuit can be detected. The number of interrupters per second can be determined by photographing the phenomenon and counting the number of partial discharges in one ascent of the arc, the time occupied in the ascent being noted.

Third. Short intervals of time can be measured by using as the primary an alternating current of known frequency. The time of exposure given by a camera shutter, for example, can be determined by focusing the camer
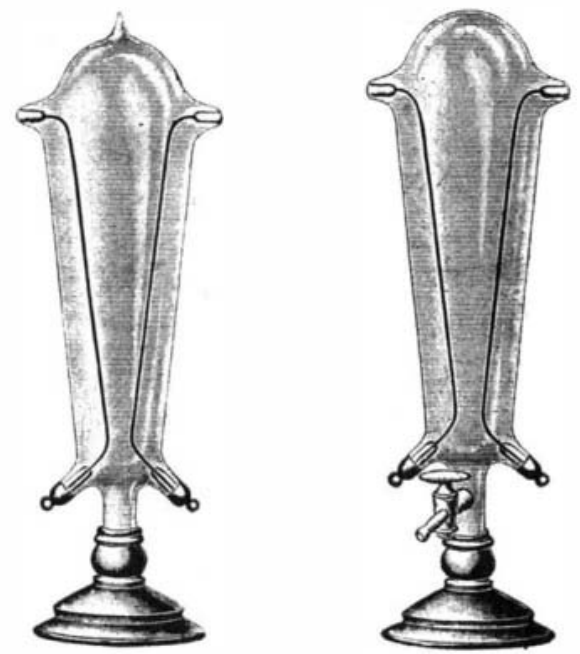

Fig. 2.-Horn electrodes in vacuum tubes.

on the tube and snapping the shutter while the discharge is passing. If the primary current is one of 50 cycles, or 100 alternations, per second, and 5 luminous tongues appear on the ground glass, the time of exposure is 0.05 second. more easily remembered than these are crossed nail imprints for the queen of spades (kreuz, or cross, is on of the German names for the spade suit), and two scratches, forming a V, or half diamond, for the queen of diamonds. One pack is marked very sparingly; en another is overloaded with marks, as if it had been prepared by a person who distrusted his ability to differentiate the symbols. These nail imprints are felt and
recognized by the finger tips, which often are prepared recognized by the finger tips, which
for the task by chemical treatment.

Other fraudulent cards bear lead pencil marks, usually in the form of dots, apparently so casual and unsystematic that it is very difficult to discover their significance. These pencil marks seem intended for the eye, as they are imperceptible to the touch, though it cannot be asserted with confidence that they canno be felt by the sensitive fingers of the skilled gambler.

One pack of cards, definitely known to have bee used for the purpose of cheating, appeared absolutely normal. It bore neither pencil marks nor nail imprints, and showed no evidence of artificial roughening of the edges by scraping with a knife, of perforation with a ho needle covered with melted wax (to fill the perforations) or of the removal of the glaze from any card.

It was a German skat pack of 32 cards. The back were covered with the so-called "lightning" pattern,

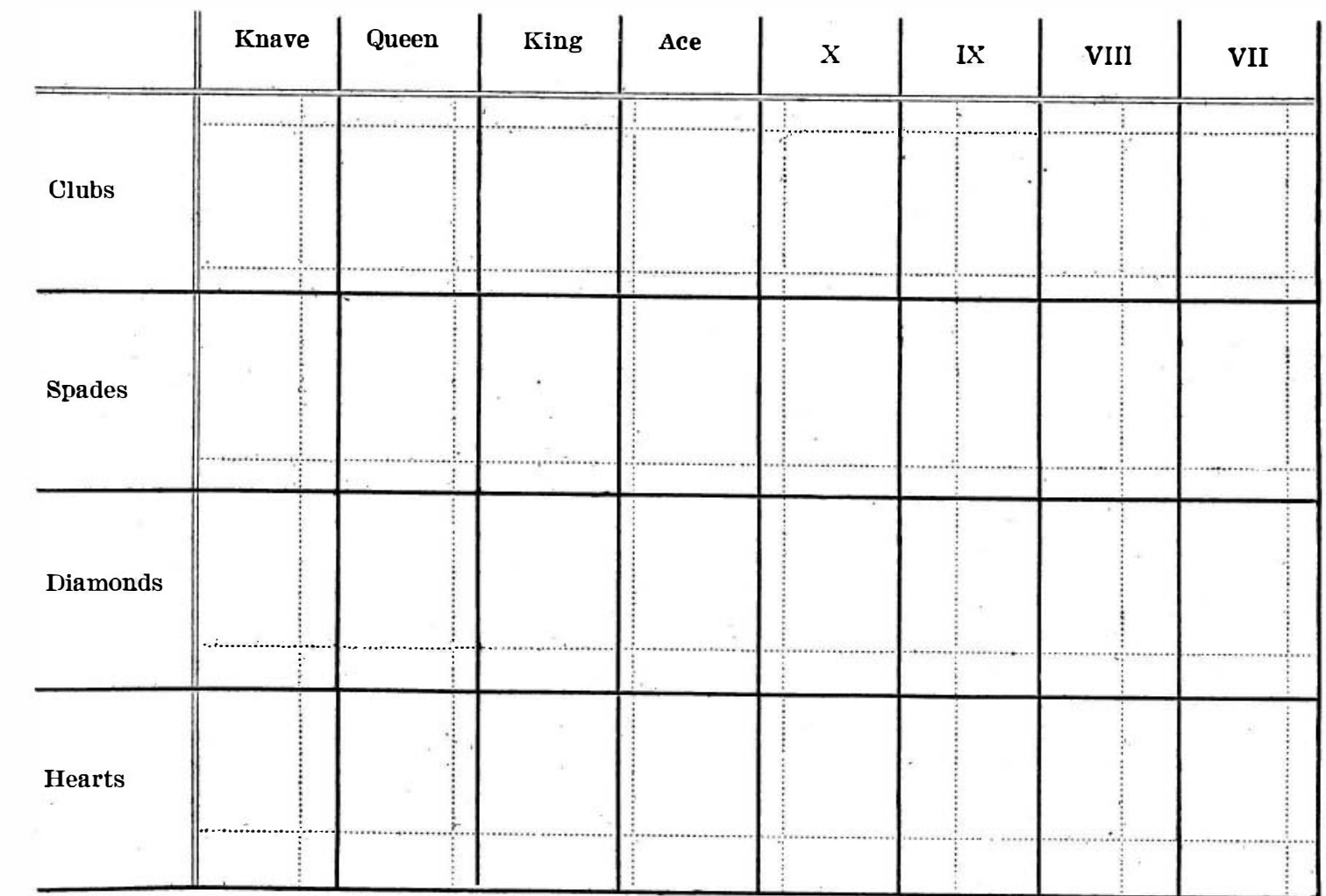

Fig. 2.-Diagram explaining distinguishing pattern on card backs.

consisting of short and thick "zigzag" black and red lines, scattered irregularly over a white ground. Careful examination, however, revealed a peculiar figure which occupied a different position on the back of each card, except the four kings, on which it did not occur. The ends of this figure are indicated by the terminations of the lines $M$ and $D$, which have been drawn across the photograph of one of the cards (Fig. 1). When all of the cards were laid, face down, in four rows, according to suit and relative rank in skat, as is indicated in the diagram (Fig. 2), it became evident that the cards, while thus arranged, had been printed with a regularly recurring pattern, shorter and broader than themselves. The repeats of this pattern are bounded by the dotted lines in the diagram. The peculiar figure lies on the vertical dotted lines, and the diagram explains its absence from the kings and its varying position on the other cards.

It is evident, therefore, that this very talented swindler recognized the cards by the slight variations in the position of the pattern on their backs. There are two such packs in the criminal institute of the University of Graz and it may be assumed that other cards, as innocent in appearance as those of the "lightning" pattern, are equally well adapted for cheating and are successfully mployed for that purpose. 